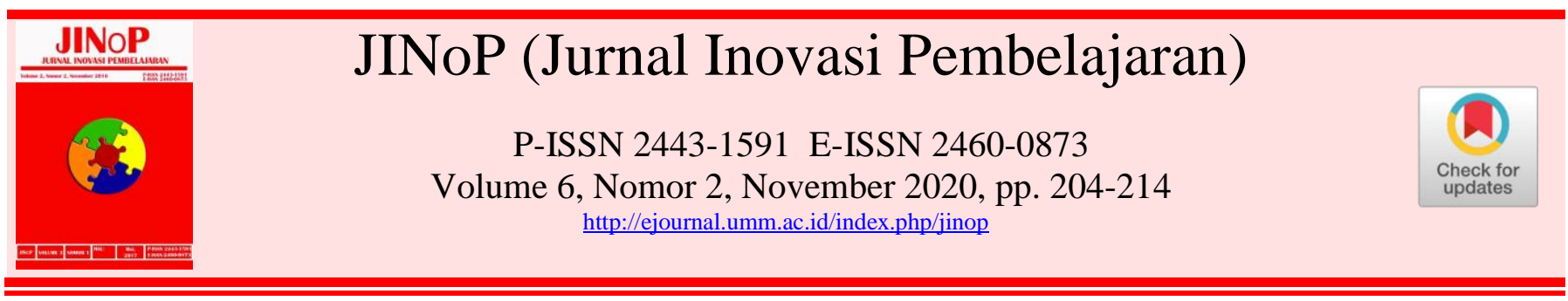

\title{
Efektifitas pembelajaran sejarah kebudayaan Islam melalui google classroom ditinjau dari hasil belajar siswa
}

\author{
Ossi Marga Ramadhan ${ }^{1)^{*}}$, Tarsono ${ }^{2)}$ \\ ${ }^{1}$ Program Studi Pendidikan Agama Islam, Pascasarjana, UIN Sunan Gunung Djati, Jl. A.H \\ Nasution No. 105A, Bandung, Indonesia \\ ${ }^{2}$ Program Studi Pendidikan Agama Islam, Pascasarjana, UIN Sunan Gunung Djati, Jl. A.H \\ Nasution No. 105A, Bandung, Indonesia
}

ossimarga33@gmail.com*; tarsono@uinsgd.ac.id

*Penulis Koresponden

\section{ABSTRAK}

Imbas Covid-19 dalam dunia pendidikan memaksa pendidik untuk berinovasi dalam mengembangkan dan mengalihkan proses pembelajaran konvensional ke pembelajaran jarak jauh. Salah satu platform pembelajaran jarak jauh adalah google classroom. Tujuan penelitian ini mendeskripsikan keefektifan pembelajaran daring melalui google classroom yang ditinjau dari hasil belajar siswa. Penelitian ini berjenis quasi experiment yang dirancang memakai one group pretest-postest design. Sampel penelitian ini menggunakan seluruh siswa di kelas 11 yang berjumlah 31 orang pada salah satu sekolah di Kabupaten Purwakarta, kemudian data diolah dengan uji paired sample t test serta $N$-Gain. Hasil penelitian menggambarkan bahwa pembelajaran jarak jauh menggunakan google classroom apabila ditinjau dari hasil belajar siswa mencapai persentase $58.3 \%$ (cukup efektif menurut tafsiran $N$-Gain). Hal ini berkaitan dengan pelaksanaan pembelajaran dibandingkan sebelum menggunakan google classroom mengalami peningkatan rata-rata hasil belajar sebesar 22.6\%. Namun, disisi lain ditemukan beberapa kelemahan dalam pembelajaran tersebut seperti penguasaan fitur, siswa tidak memiliki paket data, serta jangkauan sinyal yang tidak merata. Kesimpulan penelitian menunjukkan bahwa penggunaan Google classroom cukup efektif dalam pembelajaran sejarah kebudayaan Islam ditinjau dari hasil belajar siswa.

Kata kunci: Google Classroom; Hasil Belajar; Sejarah Kebudayaan Islam.

\section{ABSTRACT}

The impact of current covid-19 has succeeded in changing various educational aspect, thus forcing educators to develop and diverting conventional learning processes into distance learning. One of the distance learning platforms is google classroom. During the Covid-19 pandemic, this application became of its own urgency because of the many features presented to support learning. This research employed a quasi-type experiment design by using a one-group pretest-postest design, which aims to determine the google classroom's effectiveness on Islamic Cultural History learning from the perspective of student learning outcomes. This research employed all students in grade 11 with total of 31 people at one of the MA in Purwakarta Regency. The the data were processed by using the paired-sample t-test and N-Gain. The results of the research illustrate that distance learning by using google classroom when viewed from student learning outcomes, reaches a percentage of $58.3 \%$ (quite effective according to the interpretation of $\mathrm{N}$-Gain). The result related to the implementation of learning compared to before using Google Classroom, showed an increase in average learning outcomes of $22.6 \%$. However, several weaknesses were found in the learning process, such as mastery of features, students not having data packages, and uneven signal coverage. The conclusion of this research showed that the use of Google classroom is quite effective in learning the history of Islamic culture in terms of student learning outcomes.

Keywords: Google Classroom; History Of Islamic Culture; Learning Outcomes. 
diunggah: 2020-07-16, direvisi: 2020-11-02, diterima: 2020-11-20, dipublikasi: 2020-11-20

Copyright (c) 2020 Ramadhan et al

This is an open access article under the CC-BY license

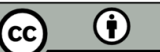

Cara sitasi: Ramadhan, O.M., \& Tarsono, T. (2020). Efektifitas pembelajaran sejarah kebudayaan Islam melalui google classroom ditinjau dari hasil belajar siswa. JINoP (Jurnal Inovasi Pembelajaran), 6(2). 201-214. https://doi.org/10.22219/jinop.v6i2.12927

\section{PENDAHULUAN}

Mata pelajaran sejarah kebudayaan Islam banyak menerangkan mengenai perjalanan hidup umat Islam dari satu fase menuju fase yang lainnya dalam memperjuangkan usaha bersyariah dan menebarkan akhlak serta akidah (Euis, 2016). Nilai-nilai Islam yang ditanamkan adalah untuk mengetahui kejayaan yang pernah diraih umat muslim untuk lebih meneguhkan keyakinan siswa tentang kebenaran agama Islam. Upaya meneladani tokoh yang membawa misi Islam seperti para-Nabi Khulafaur Rasyidin dan alim ulama lainnya juga penting untuk diketahui oleh siswa. Hal ini mengindikasikan bahwa upaya untuk menggali ibrah pada setiap fase sejarah yang dilalui umat muslim adalah hal perlu dilakukan oleh guru kepada siswa (Nurjannah, 2016). Sehingga di dalam pembelajaran, guru sebagai pemantik nalar siswa harus mampu menelusuri hikmah, dalil, nilai, maupun teori dari fakta sejarah yang ada, dengan harapan siswa dapat menangkap makna yang terkandung di dalamnya.

Kondisi di lapangan menunjukkan keadaan siswa yang sering merasa jenuh dalam mempelajari Sejarah Kebudayaan Islam, terlebih jika metode yang digunakan selalu menggunakan ceramah (Fauziyah, 2013). Hal ini membutuhkan tingkat kreatifitas guru dalam menetapkan metode pembelajaran yang cocok agar proses kegiatan belajar Sejarah Kebudayaan Islam (SKI) mampu meraih tujuan yang diharapkan (Herlina, 2016). Banyak guru maupun peneliti yang mencoba memadukan model pembelajaran dalam pelajaran SKI untuk mencapai hasil belajar yang maksimal. Seperti Fitria (2019) yang dalam penelitiannya menggunakan model scramble berbasis powerpoint, ternyata mampu menaikkan rata-rata capaian hasil pembelajaran siswa pada mata pelajaran SKI. Begitu juga Nisa (2020) secara signifikan berhasil meningkatkan hasil pembelajaran SKI dengan melalui metode SAVI.

Pembelajaran SKI di MA Muttaqien Purwakarta sebelumnya menggunakan model Mind Mapping. Siswa yang diajarkan oleh model mind mapping jauh lebih mudah menyerap informasi yang diterima, karena tujuan kinerjanya menyelaraskan kemampuan otak kanan dan otak kiri secara maksimal (Hidayatusholikah, 2018). Hal ini tepat apabila diterapkan di dalam kelas pada pembelajaran Sejarah Kebudayaan Islam yang bersifat hafalan. Akan tetapi saat situasi pandemik Covid-19, pemerintah memberlakukan kebijakan beraktivitas dari rumah dengan model pembelajaran jarak jauh (Mittelmeier et al., 2019; Gunawan et al., 2020). Pembelajaran jarak jauh merupakan bentuk solusi dalam mengatasi sulitnya pembelajaran secara langsung pada situasi pandemik seperti sekarang ini (Kusuma, J. W. \& Hamidah, 2020). Hampir semua pendidik menggunakan aplikasi daring (Yensy, 2020) seperti mengunakan chatting, Video conference maupun dengan berkirim e-mail (Rahmawati, 2016).

Aplikasi pembelajaran yang saat ini sedang diminati oleh pendidik maupun peserta didik, termasuk para guru dan siswa di MA Muttaqien Purwakarta adalah 
Google Classroom. Aplikasi Google Classroom dapat memudahkan guru dalam membuat dan membagikan materi pembelajaran, karena di dalamnya terdapat fitur-fitur yang membantu guru dalam melaksanakan prosses pembelajaran, diantaranya menghimpun tugas, serta menilai atau memberikan respon dari tugas siswa (Aris et al., 2019; Maskar \& Wulantina, 2019). Instrumen yang dapat dikelola oleh guru meliputi menu materi, menu tugas, menu latihan soal, menu penilaian dan menu absensi (Ahmad, 2020). Banyak peneliti menunjukkan secara signifikan bahwa penggunaan Google classroom mampu memacu motivasi dan hasil belajar peserta didik (Huda et al., 2019; Arruji 2018; Burhanudin, 2019). Begitupula ketika media tersebut diterapkan pada mata pelajaran SKI mampu meningkatkan motivasi, aktifitas dan kreatifitas siswa walaupun penelitian ini dilakukan jauh sebelum pandemi Covid-19 menyerang Indonesia (Euis, 2017).

Kaitan hasil belajar dengan penggunaan model pembelajaran jarak jauh dengan Google Classroom masih menjadi polemik dikalangan stakeholder dan masyarakat (Darmalaksana et al., 2020). Hal ini dikarenakan minimnya interaksi antara guru dan peserta didik dan guru cenderung memberikan tugas sehingga peserta didik merasa terbebani (Kusuma, J. W. \& Hamidah, 2020). Hal tersebut dikarenakan pembelajaran jarak jauh belum dianggap lebih baik daripada pembelajaran konvensional seperti biasa, terutama pada pelajaran yang membutuhkan penalaran dan pemahaman konsep seperti pada mata pelajaran SKI, dibandingkan dengan pembelajaran sebelumnya (Fuady, 2016). Menurut Suryani (2020) pemahaman konsep dalam sejarah adalah merupakan tolak ukur seberapa jauh peserta didik mampu menerima materi yang disajikan. Selain itu, siswa mampu menerangkan sendiri pemahaman yang didapat melalui bahasanya sendiri.

Oleh karena itu, pada masa pandemic seperti saat ini pengetahuan mengenai keberhasilan siswa dalam pembelajaran SKI melalui google classroom perlu diteliti. Penting untuk dianalisis apakah pembelajaran pembelajaran ini berhasil secara optimal atau sebaliknya, sehingga dapa dicari solusi untuk mengatasinya dalam upaya meningkatkan keberhasilan dalam pembelajaran. Penelitian ini memiliki tujuan untuk mengetahui keefektifan pembelajaran daring melalui google classroom yang ditinjau dari hasil pembelajaran saat pandemik, yang akhir-akhir ini sering diterapkan.

\section{METODE}

Penelitian ini menggunakan jenis penelitian quasi experiment dan dirancang menggunakan one group pretest-postest design, yang dilakukan untuk mengetahui akibat dari perlakuan dengan membandingkan hasil belajar dua kelompok waktu dengan kelas yang sama (dependent class). Terbagi menjadi dua kelompok eksperimen, yakni sebelum menggunakan media Google Classroom atau sebelum Penilaian Tengah Semester (PTS) dan sesudah menerapkan media Google Classroom pada kelas yang sama.

Populasi pada penelitian ini adalah seluruh murid kelas 11 di MA Muttaqien Purwakarta yang berjumlah 31 orang, apabila populasi kurang dari 100 maka seluruhnya dijadikan sampel (Yensy, 2020). Data diperoleh dari hasil Penilaian Tengah Semester untuk kelompok pertama dan hasil Penilaian Akhir Semester untuk kelompok kedua. Kemudian data diolah menggunakan software SPSS versi 26 dengan terlebih dahulu dianalisis secara deskriptif, lalu diuji normalitas data. Kemudian dilakukan uji $t$-dependent atau uji paired sample t tes, 
selanjutnya menghitung skor Gain (uji $N$-gain) yaitu untuk mengetahui efektifitas penggunaan media Google Classroom dalam pembelajaran sejarah kebudayaan islam. Dengan rumus dari Hake (Yensy, 2020) kemudian perolehan nilai $N$-gain score ditentukan ke dalam bentuk prosentase. Adapun rumus tersebut adalah sebagai berikut. Perolehan nilai N-gain kemudian dikategorisasi dalam bentuk persentase (Hake, 1999) yang tercantum pada Tabel 1. di bawah ini.

Tabel 1. Kategori Tafsiran Efektifitas N-Gain

\begin{tabular}{cc}
\hline Persentase $(\%)$ & Tafsiran \\
\hline$<40.00$ & Tidak Efektif \\
$40.00-55.99$ & Kurang Efektif \\
$56.00-75.00$ & Cukup Efektif \\
$>75.00$ & Efektif \\
\hline
\end{tabular}

\section{HASIL DAN PEMBAHASAN}

Hasil penelitian menunjukkan bahwa dari seluruh data sampel mengalami peningkatan hasil belajar siswa dari Penilaian Tengah Semester ke Penilaian Akhir Semester. Hal ini mengindikasikan bahwa rata-rata nilai ujian peserta didik mengalami kenaikan setelah menggunakan media Google Classroom sebesar 22.6\%. Nilai minimal yang sebelumnya adalah 50 meningkat menjadi 76 . Begitupula dengan nilai maksimal yang mencapai 95. Selanjutnya nilai skewness yang mendekati nol dari keduanya secara deskriptif menunjukkan data tersebut terdistribusi normal. Data dapat dilihat pada Tabel 2 di bawah ini.

Tabel 2. Deskriptif Data

\begin{tabular}{cccccccc}
\hline & \multicolumn{9}{c}{ Deskriptif Statistik } \\
\hline & & & & & \multicolumn{2}{c}{ Kemiringan } \\
\cline { 5 - 7 } Kel. & \multirow{2}{*}{ Jumlah } & Minimal & Maksimal & $\begin{array}{c}\text { Rata- } \\
\text { rata }\end{array}$ & $\begin{array}{c}\text { Standar } \\
\text { Deviasi }\end{array}$ & Statistik & $\begin{array}{c}\text { Standar } \\
\text { Error }\end{array}$ \\
\hline PTS & 31 & 50 & 83 & 62.48 & 8.86 & 0.41 & 0.42 \\
PAS & 31 & 76 & 95 & 85.03 & 5.13 & 0.38 & 0.42 \\
\hline
\end{tabular}

Setelah diketahui rata-rata data mengalami peningkatan, selanjutnya dilakukan pengujian melalui dua alat uji yakni Kolmogorov-Smirnov dan ShapiroWilk, hasilnya menunjukkan semua nilai signifikansi pada keduanya adalah melebihi dari 0.05, maka diketahui secara signifikan data tersebut dapat dikatakan normal (pada Tabel 3).

Tabel 3. Pengujian normalitas data

\begin{tabular}{ccccccc}
\hline \multicolumn{7}{c}{ Kolmogorov Smirnov } \\
\cline { 2 - 7 } Kel. & Statistik & Jumlah & $\begin{array}{c}\text { Nilai } \\
\text { Signifikansi }\end{array}$ & Statistik & Jumlah & $\begin{array}{c}\text { Nilai } \\
\text { Signifikansi }\end{array}$ \\
\hline PTS & 0.126 & 31 & $0.200^{*}$ & 0.952 & 31 & 0.179 \\
PAS & 0.139 & 31 & 0.134 & 0.942 & 31 & 0.095 \\
\hline
\end{tabular}

Dilakukan pengujian perbedaan rata-rata menggunakan t-paired test. Hasilnya terlihat nilai signifikansi adalah 0.000 , hal ini menggambarkan pada pengujian ini mendapati hasil yang berbeda dengan siginifikan, dengan standar deviasi yang mencapai 8.71(Tabel 4). 
Tabel 4. Paired Samples Test

\begin{tabular}{|c|c|c|c|c|c|c|c|c|}
\hline \multicolumn{9}{|c|}{ Uji Sampel Berpasangan } \\
\hline \multirow[b]{3}{*}{ Kel. } & \multicolumn{5}{|c|}{ Perbedaan } & \multirow[b]{3}{*}{$\mathrm{t}$} & \multirow[b]{3}{*}{ df } & \multirow[b]{3}{*}{$\begin{array}{l}\text { Nilai } \\
\text { Sig. }\end{array}$} \\
\hline & \multirow[b]{2}{*}{$\begin{array}{c}\text { Rata- } \\
\text { rata }\end{array}$} & \multirow[b]{2}{*}{$\begin{array}{l}\text { Standar } \\
\text { Deviasi }\end{array}$} & \multirow[b]{2}{*}{$\begin{array}{c}\text { Standar } \\
\text { Error }\end{array}$} & \multicolumn{2}{|c|}{ Taraf Keyakinan 95\% } & & & \\
\hline & & & & Terbawah & Teratas & & & \\
\hline $\begin{array}{l}\text { PTS- } \\
\text { PAS }\end{array}$ & -22.5 & 8.71 & 1.56 & -25.7 & -19.3 & -14.4 & 30 & 0.00 \\
\hline
\end{tabular}

Setelah data hasil belajar diketahui memiliki perbedaan, kemudian dilakukan pengujian melalui $N$-gain Score, hasil persentase $N$-gain sebesar $58.28 \%$. Persentase tersebut menunjukkan pembelajaran sejarah kebudayaan islam dengan menggunakan media Google Classroom cukup efektif. (Tabel 5).

Tabel 5. Persentase N-Gain

\begin{tabular}{lcc}
\hline & Prosentase N-Gain (\%) & \\
\hline & Statistik & Standar Error \\
Rata-rata & 58.2 & 33.1 \\
\hline
\end{tabular}

Efektifitas tersebut dibuktikan dengan peningkatan hasil pembelajaran siswa. Senada dengan penelitian Maskar (2019) media google classroom mampu meningkatkan pemahaman maupun hasil belajar peserta didik,sebab di dalam prosesnya disajikan secara efektif dan menarik, sikap belajar siswa cenderung menjadi mandiri dan termotivasi, serta memberikan keaktifan dan kreatif. Begitupula Rachman (2020) mengatakan bahwa melalui aplikasi google classroom pembelajaran diarahkan untuk siswa dapat menerima materi dengan baik dan benar serta mengemukakan pendapat atau hasil yang sudah dipelajari. Karena di dalam Google Classroom terdapat fitur Communication yang memungkinkan guru dengan peserta didik dapat berinteraksi secara langsung, bahkan untuk melakukan diskusi, dan apabila diperlukan media tambahan berbentuk vidio dari kanal youtube, dapat dilampirkan pada fitur ini (Kusuma et al. 2020). Fitur yang tersedia lainnya dalam upaya meningkatkan pemahaman pembelajaran siswa adalah Archive Course, fitur ini menyimpan instrumen pembelajaran yang telah diberikan oleh guru. Hal ini memudahkan siswa dalam mengakses kembali materi pembelajaran sebelumnya. Selain itu, fitur penugasan (Assignment) yang dihadirkan dapat mengingatkan siswa kapan tepatnya jadwal pengumpulan tugas, selain itu guru juga dapat memberikan nilai secara langsung pada fitur tersebut.

Dengan demikian, pada masa pandemik yang tidak memungkinkan untuk melakukan pembelajaran secara langsung, google classroom dapat menjadi sarana alternatif media pembelajaran yang efektif untuk tetap melaksanakan diskusi dan komunikasi jarak jauh antara guru dengan muridnya. Sehingga guru dan siswa dapat melaksanakan interaksi pembelajaran dengan lebih leluasa (Ahmad, 2020). Akan tetapi tidak dapat dipungkiri bahwa google classroom dengan berbagai fitur andalannya yang dapat membantu pembelajaran menjadi efektif tersebut tidak luput dari beberapa kekurangan. Seperti halnya pada hasil wawancara yang dilakukan peneliti secara langsung kepada siswa adalah ketika awal perpindahan kepada pembelajaran jarak jauh, beberapa siswa sering mengeluhkan penggunaan pembelajaran berbasis daring sebab sebelumnya belum pernah menggunakan media berbasis daring pada proses pembelajaran. Namun hal tersebut teratasi ketika guru perlahan menjelaskan cara penggunaan pembelajaran melalui google 
classroom, sesuai dengan pernyataan Tarsono (2010) bahwa di dalam proses belajar, perlahan manusia mampu memahami diri sendiri, mengamati dan mempelajari lingkungannya.

Selain itu siswa merasa bahwa di dalam pembelajaran menjadi kurang efisien, sebab mengharuskan siswa mempunyai paket data setiap kali melakukan pembelajaran, sedangkan seluruh mata pelajaran dilakukan secara daring dan mengharuskan memiliki paket data khusus untuk pembelajaran sementara tidak semua siswa di setiap harinya memiliki paket data yang tersedia (Maskar \& Wulantina, 2019). Demikian pada siswa yang berada pada jangkauan sinyal yang tidak stabil, mengakibatkan beberapa siswa ketinggalan dalam mempelajari materi (Rozak \& Albantani, 2018). Senada dengan penelitian Ichsan (2020) yang menunjukkan pelaksanaan pembelajaran daring mengalami beberapa kendala, ketidakstabilan koneksi internet, serta materi yang disajikan kurang dipahami oleh peserta didik. Sedangkan pemahaman tersebut mempengaruhi pada hasil belajar (Tambunan \& Bukit, 2015). Menurut Susmiati (2020) untuk meningkatkan pemahaman tersebut maka guru harus mampu memotivasi siswa melalui model pembelajaran yang tepat, agar pemahaman siswa menjadi optimal dan diharapkan pada situasi pandemik ini hasil pembelajaran siswa menjadi semakin meningkat. Kelebihan dan kekurangan pembelajaran menggunakan Google Classroom dirangkum dalam Tabel 6.

Tabel 6. Kelebihan dan kekurangan pembelajaran melalui google classroom

\begin{tabular}{|c|c|}
\hline Kelebihan & Kekurangan \\
\hline $\begin{array}{l}\text { Fitur komunikasi yang tersedia dapat memberikan } \\
\text { kemudahan bagi penggunanya untuk berdiskusi } \\
\text { secara langsung. }\end{array}$ & $\begin{array}{l}\text { Ditemukan siswa kesulitan menggunakan fitur } \\
\text { pada awal peralihan pembelajaran melalui } \\
\text { google classroom. }\end{array}$ \\
\hline Sistem penugasan yang memudahkan. & $\begin{array}{l}\text { Pembelajaran menjadi kurang efisien ketika } \\
\text { siswa tidak memiliki paket data. }\end{array}$ \\
\hline $\begin{array}{l}\text { Fitur Archive Course yang memudahkan siswa } \\
\text { mempelajari kembali materi yang telah terlewat. } \\
\text { Bebas iklan. }\end{array}$ & Jangkauan sinyal yang tidak merata. \\
\hline
\end{tabular}

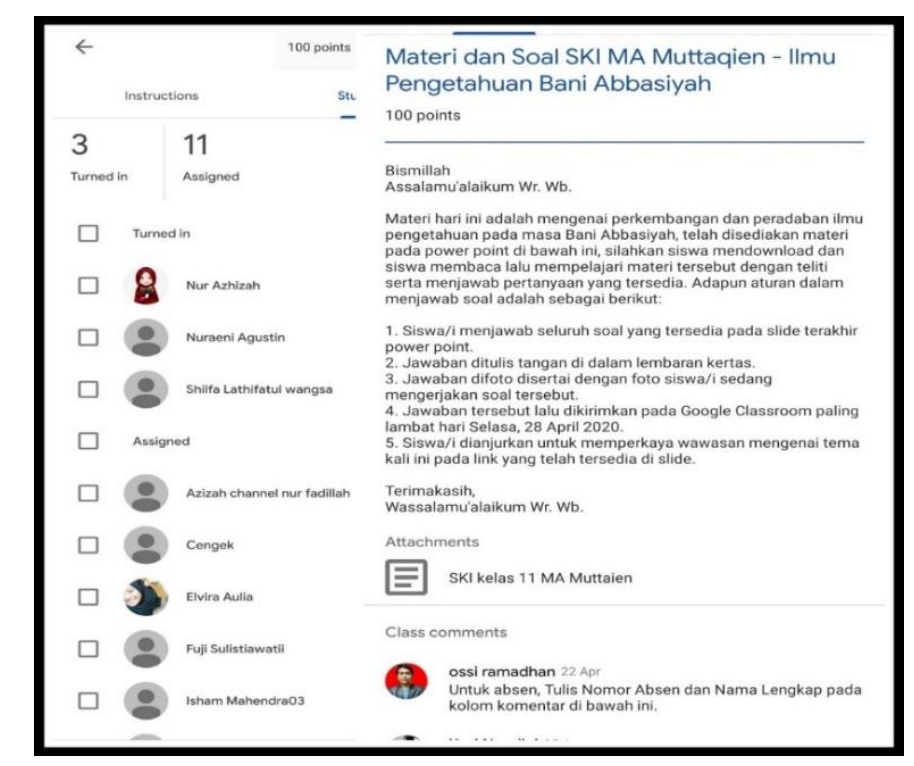

Gambar 1. Aktifitas pembelajaran melalui google classroom. 
Gambar 1 menunjukkan kegiatan pembelajaran sejarah kebudayaan islam dan Gambar 2 menunjukkan instruksi yang diberikan guru melali google classroom. Aktivitas tersebut menunjukkan pemberian materi dan penugasan yang diberikan dengan mudah, karena dapat dikerjakan dimanapun siswa berada. Sehingga ketika siswa belum mengerti mengenai materi yang diberikan, siswa dapat menanyakan kapanpun atau bahkan ketika melakukan diskusi aktif antara siswa semuanya dilakukan pada satu aplikasi saja (Rozak \& Albantani, 2018). Pengumpulan tugas pun dapat dilihat sangat rinci dari mulai batas akhir pengumpulan hingga siapa saja yang telat maupun tidak mengumpulkan. Pun kehadiran siswa dapat dilihat begitu guru menyediakan kolom absensi.

Peran guru disini berada pada posisi yang sentral, artinya guru harus benarbenar memahami segala fitur yang tersedia agar pembelajaran melalui google classroom dapat berjalan dengan optimal. Seperti mengaitkan antara satu aplikasi pembelajaran dengan aplikasi pembelajaran yang lain di google classroom (Indiani, 2020). Hal ini dilakukan agar pembelajaran tidak berjalan secara monoton sehingga peserta didik mampu memahami lebih dalam materi yang disampaikan dan meningkatkan semangat belajar ditengah pembelajaran jarak jauh (Ammy, 2020). Google Classroom dapat memicu keaktifan dan motivasi peserta didik di dalam pembelajaran. Senada dengan penelitian Ali (2020) yang menemukan bahwa pemanfaatan media google classroom dalam pembelajaran dapat memacu motivasi bahkan prestasi belajar peserta didik. Oleh karena itu, pemanfaatan teknologi bagi mata pelajaran SKI menjadi urgensi tersendiri dalam kegiatan pembelajaran, terlebih ketika kondisi pandemi covid-19 seperti saat ini. Begitupun menurut Song (2015) bahwa pesatnya perkembangan teknologi menjadi kesempatan yang besar untuk mengembangkan proses pembelajaran.

telah memberikan materi penjelasan mengenai tema tersebut yang tersedia pada link Youtube di bawah ini:

https://youtu.be/4_ARjPcEH4w

https://youtu.be/4_ARjpcEH4w

https://youtu.be/4_ARjPcEH4w

Silakan kalian amati dan pelajari materi yang disampaikan dengan teliti, agar kalian memahami substansi yang Bapak sampaikan pada vidio tersebut.

Setelah itu kalian kerjakan beberapa soal dan upload tugas vidio yang ada pada link berikut:

https://forms.gle/gVAkAz9g $\underline{3 i k z N A q h 7}$

https://forms.gle/gVAkAz9g3ikzNAgh7

https://forms.gle/gVAkAz9g3ikzNAqh7

Jawaban yang paling jujur adalah yang terbaik, bukan jawaban paling baik namun hasil dari ketidakjujuran, itu yang sangat Bapak hargai.

Salah satu soal meminta kalian untuk membaca Al-Qur'an sambil merekam melalui vidio (bukan audio), hasil vidio tersebut bisa kalian upload pada link di atas, namun jika mengalami kendala bisa kalian upload pada Google Classroom, apabila masih mengalami kendala juga boleh kirim via WhatsApp di nomor 081911695743.

Absensi diisi sesuai dengan tanggal pada hari ini, pada link berikut:

https://forms.gle/7kgBfuWumhvPmF1RA

https://forms.gle/7kgBfuWumhvPmF1RA

https://forms. gle/7kgBfuWumhvPmF1RA

Gambar 2. Pemberian instruksi melalui google classroom.

Penelitian ini memberikan gambaran bahwa pembelajaran melalui media daring dapat membantu siswa belajar secara mandiri, memberikan motivasi, 
meningkatkan keaktifan dan hasil belajar siswa, termasuk melalui google classroom. Tentu dengan syarat bahwa guru harus menguasai dan memanfaatkan perkembangan teknologi ke dalam pembelajaran secara optimal. Sebagaimana pemanfaatan teknologi dapat meningkatkan hasil belajar siswa menurut penelitian (Delfisanur et al., 2020; Setyaningsih et al., 2020; Kusuma et al., 2020; dan Toyib, 2012).

Berdasarkan uraian di atas, maka pembelajaran sejarah kebudayaan islam dengan memanfaatka google classroom cukup efektif jika dilihat dari segi hasil belajar siswa. Sebab diketahui hasil pembelajaran sesudah penggunaan google classroom menunjukkan hasil yang lebih baik jika dibandingkan dengan hasil sebelumnya. Namun, masih terdapat kelemahan selama pembelajaran online berlangsung, seperti ketidaksiapan sarana dan prasarana penunjang kegiatan pembelajaran daring serta sumber daya manusia dalam memanfaatkan teknologi dan berinovasi merubah cara dan sistem pembelajaran, terkhusus saat kondisi pandemik covid-19 seperti saat ini.

\section{SIMPULAN}

Penggunaan media google classroom pada pembelajaran sejarah kebudayaan Islam dapat menunjang proses pembelajaran dengan cukup efektif terhadap hasil belajar siswa. Hal ini terbukti dengan hasil pembelajaran sesudah menggunakan google classroom lebih baik daripada sebelumnya dengan peningkatan rata-rata sebesar $22.6 \%$. Begitu juga dengan kategorisasi efektifitas $N$-Gain yang memperoleh prosentase sebesar $58.2 \%$ yang berada pada rentang $56-$ $75 \%$ dengan tafsiran yang cukup efektif.

Dari kendala yang dihadapi ketika melakukan pembelajaran menggunakan google classroom, peneliti memiliki saran agar pemerintah sebagai pemangku kebijakan dapat mengatasi masalah tersebut dengan melengkapi seluruh kebutuhan baik pada aspek sarana dan prasarana maupun mengadakan pelatihan bagi guru agar menguasai dan berinovasi dalam memanfaatkan konten, agar materi yang disajikan pada murid lebih menarik. Tentu bukan hanya pada media google classroom saja, namun pada seluruh media pembelajaran berbasis online.

\section{DAFTAR PUSTAKA}

Agung Mahardini, M. M. (2020). Analisis situasi penggunaan google classroom pada pembelajaran daring fisika. Jurnal Pendidikan Fisika, 8(2), 215. doi: https://doi.org/10.24127/jpf.v8i2.3102

Ahmad, A. (2020). Efektivitas pembelajaran daring dengan menggunakan google classroom pada mata pelajaran matematika di madrasah aliyah darul falah Batu Jangkih. El-Hikam, 13(1), 66-82. Diambil dari https://ejournal.kopertais4.or.id/sasambo/index.php/elhikam/article/view/389 5

Ali, L. U., \& Zaini, M. (2020). Pemanfaatan program aplikasi google classroom sebagai upaya meningkatkan motivasi dan prestasi belajar mahasiswa pada perkuliahan dasar-dasar kependidikan. SOCIETY, 11(1), 27-34. Diambil dari https://journal.uinmataram.ac.id/index.php/society/article/view/2297

Ammy, P. M. (2020). Analisis motivasi belajar mahasiswa menggunakan video pembelajaran sebagai alternatif pembelajaran jarak jauh (PJJ). JURNAL MATHEMATIC PAEDAGOGIC, 5(1), 27-35. Diambil dari http://jurnal.una.ac.id/index.php/jmp/article/view/1354 
Arahmat, Y., Suratno, S., \& Wahono, B. (2017). The effect of problem based learning model with mind mapping technique on biology learning achivement. Pancaran Pendidikan, 6(2), 125-132. doi: https://doi.org/10.25037/pancaran.v6i2.39

Aris, N., Erawaty, N., Massalesse, J., Sirajang, N., Wahda, W., Kasbawati, K., Jaya, A. K. (2019). Peningkatan kualitas pembelajaran matematika bagi guru sma melalui media google classroom dan geogebra. JATI EMAS (Jurnal Aplikasi Teknik dan Pengabdian Masyarakat), 3(2), 196-200. Diambil dari http://www.journal.fdi.or.id/index.php/jatiemas/article/view/253

Arruji, E. (2020). Pengaruh media google classroom terhadap hasil belajar pada konsep istem gerak. UIN Syarif Hidayatullah Press. Diambil dari http://repository.uinjkt.ac.id/dspace/handle/123456789/51034

Darmalaksana, W., Hambali, R., Masrur, A., \& Muhlas, M. (2020). Analisis pembelajaran online masa WFH Pandemic Covid-19 sebagai tantangan pemimpin digital abad 21. Karya Tulis Ilmiah (KTI) Masa Work From Home (WFH) Covid-19 UIN Sunan Gunung Djati Bandung. Jurnal Fakultas Ushuluddin. Diambil dari http://digilib.uinsgd.ac.id/30434/

Delfisanur, D., Sari, D. Y., Hasanuddin, H., \& Ambiyar, A. (2020). Pengaruh media pembelajaran berbasis aplikasi youtube terhadap aktifitas dan hasil belajar siswa kelas X pada mata pelajaran mesin konversi energi di SMK Negeri 1 Koto XI Tarusan. Jurnal Vokasi Mekanika (VoMek), 2(1), 53-59. Diambil dari http://vomek.ppj.unp.ac.id/index.php/vomek/article/view/85

Euis, Sofi. (2016). Pembelajaran Berbasis e-learning Pada Mata Pelajaran Sejarah Kebudayaan Islam Kelas VIII Madrasah Tsanawiyah Negeri. Jurnal Penelitian Manajemen Pendidikan, 1(1), 49-64. Diambil dari http://www.jurnal.uinbanten.ac.id/index.php/tanzhim/article/view/32

Fauziyah, N. (2013). Faktor penyebab kejenuhan belajar sejarah kebudayaan Islam (SKI) pada siswa kelas XI jurusan keagamaan di MAN Tempel Sleman. Jurnal Pendidikan Agama Islam UIN Sunan Kalijaga, 14(1), 99108. Diambil dari https://digilib.uin-suka.ac.id/11742/1/BAB I, IV, DAFTAR PUSTAKA.pdf

Fitria, D., \& Andriesgo, J. (2019). Penerapan model pembelajaran scramble berbasis powerpoint untuk meningkatkan hasil belajar siswa pada bidang studi sejarah kebudayaan Islam. J-PAI: Jurnal Pendidikan Agama Islam, 5(2). doi: https://doi.org/10.18860/jpai.v5i2.5857

Fuady, A. (2017). Berfikir reflektif dalam pembelajaran matematika. JIPMat, 1(2). doi: https://doi.org/10.26877/jipmat.v1i2.1236

Gunawan, G., Suranti, N. M. Y., \& Fathoroni, F. (2020). Variations of models and learning platforms for prospective teachers during the Covid-19 pandemic period. Indonesian Journal of Teacher Education, 1(2), 61-70. Diambil dari https://journal.publication-center.com/index.php/ijte/article/view/95

Hake, R. R. (1999). Analyzing change/gain scores. Unpublished.

Herlina, L. (2018). Meningkatkan motivasi belajar siswa melalui pendekatan problem based learning (PBL) pada pembelajaran sejarah kebudayaan Islam di MAN 2 Mataram NTB. eL-HIKMAH: Jurnal Kajian dan Penelitian Pendidikan Islam, 10(2), 237-254. https://doi.org/10.20414/elhikmah.v10i2.217

Hidayatusholikah, O. (2018). Pengaruh metode mind mapping terhadap keaktifan dan hasil belajar sejarah kebudayaan Islam siswa di MIN 1 Tulungagung. 
IAIN Tulungagung. Diambil dari http://repo.iain-tulungagung.ac.id/9931/

Huda, S., Rinaldi, A., Suherman, S., Sugiharta, I., Astuti, D. W., Fatimah, O., \& Prasetiyo, A. E. (2019). Understanding of mathematical concepts in the linear equation with two variables: Impact of e-learning and blended learning using google classroom. Al-Jabar: Jurnal Pendidikan Matematika, 10(2), 261-270. doi: https://doi.org/10.24042/ajpm.v10i2.5303

Ichsan, I. Z., Rahmayanti, H., Purwanto, A., Sigit, D. V., Kurniawan, E., Dewi, A. K., Marhento, G. (2020). Covid-19 dan e-Learning: Perubahan strategi pembelajaran sains dan lingkungan di SMP. JINoP (Jurnal Inovasi Pembelajaran), 6(1), 50-61. doi: https://doi.org/10.22219/JINOP.V6I1.11791

Indiani, B. (2020). Mengoptimalkan proses pembelajaran dengan media daring pada masa pandemi Covid-19. JURNAL SIPATOKKONG, 1(3), 227-232. Diambil dari http://ojs.bpsdmsulsel.id/index.php/sipatokkong/article/view/55

Kusuma, A. B., \& Astuti, W. (2020). Analisis penerapan media pembelajaran bahasa Arab berbasis aplikasi google classroom. Lahjah Arabiyah: Jurnal Bahasa Arab dan Pendidikan Bahasa Arab, 1(1), 67-89. Diambil dari https://journal.staimsyk.ac.id/index.php/almanar/article/view/120

Kusuma, J. W., \& Hamidah, H. (2020). Perbandingan hasil belajar matematika dengan penggunaan platform whatsapp group dan webinar zoom dalam pembelajaran jarak jauh pada masa pandemik Covid 19. JIPMat, 5(1). doi: https://doi.org/10.26877/jipmat.v5i1.5942

Maskar, S., \& Wulantina, E. (2019). Persepsi peserta didik terhadap metode blended learning dengan google classroom. INOMATIKA, 1(2), 110-121. Diambil dari Persepsi peserta didik terhadap metode blended Learning dengan Google Classroom

Mittelmeier, J., Rienties, B., Rogaten, J., Gunter, A., \& Raghuram, P. (2019). Internationalisation at a distance and at home: Academic and social adjustment in a South African distance learning context. International Journal of Intercultural Relations, 72, 1-12. https://doi.org/https://id.elsevier.com/as/authorization.oauth2

Burhanudin, M.A. (2019). Efektivitas pembelajaran pendidikan agama Islam berbasis google classroom dalam meningkatkan motivasi peserta didik (studi kasus di SMA semesta BBS Semarang). Tesis-UIN Sunan Kalijaga. Diambil dari https://digilib.uin-suka.ac.id/39082/1/17204011115_BABI_V_DAFTAR-PUSTAKA.pdf

Nisa, D. N., \& Lisnawati, S. (2020). Pengaruh metode somatic auditory visual intellectual (Savi) terhadap hasil belajar SKI. Al-Tadzkiyyah: Jurnal Pendidikan Islam, 11(1), 73-82. Diambil dari https://103.88.229.8/index.php/tadzkiyyah/article/view/6014

Nurjannah, N. (2016). Menemukan nilai karakter dalam pembelajaran sejarah kebudayaan Islam. Al-Tadabbur, 2(1), 1-12. Diambil dari http://journal.iainternate.ac.id/index.php/altadabbur/article/view/48

Rachman, H. F., Sudiana, I. K., \& Wijaya, M. A. (2020). Pengaruh model pembelajaran berbantuan aplikasi google classroom terhadap hasil belajar bola basket. JURNAL PENJAKORA, 7(1), 57-68. https://doi.org/10.23887/penjakora.v7i1.24441

Rahmawati, I. (2016). Pelatihan dan pengembangan pendidikan jarak jauh berbasis digital class platform edmodo. In Universitas Terbuka Convention 
Center.

Diambil

dari

https://scholar.google.co.id/scholar?hl=id\&as_sdt=0\%2C5\&q=Pelatihan

Rozak, A., \& Albantani, A. M. (2018). Desain perkuliahan bahasa Arab melalui google classroom. Arabiyat: Jurnal Pendidikan Bahasa Arab dan Kebahasaaraban, 5(1), 83-102. doi: https://doi.org/10.15408/a.v5i1.7481

Setyaningsih, S., Rusijono, R., \& Wahyudi, A. (2020). Pengaruh penggunaan media pembelajaran interaktif berbasis articulate storyline terhadap motivasi belajar dan hasil belajar siswa pada materi kerajaan hindu budha di Indonesia. Didaktis: Jurnal Pendidikan dan Ilmu Pengetahuan, 20(2). Diambil dari https://103.114.35.30/index.php/didaktis/article/view/4772

Song, W. W., Forsman, A., \& Yan, J. (2015). An e-curriculum based systematic resource integration approach to web-based education. International Journal of Information and Education Technology, 5(7), 495. Diambil dari https://www.researchgate.net/profile/William_Song6/publication/272910896. pdf

Suryani, R. S., \& Nugroho, G. (2020). Meningkatkan pemahaman konsep sejarah agama islam melalui strategi indexii card match di kelas XII MA Syifa'ul Qulub. Jurnal Pendidikan Agama Islam Indonesia, 1(1), 28-47. doi: https://doi.org/10.37251/jpaii.v1i1.63

Susmiati, E. (2020). Meningkatkan motivasi belajar bahasa indonesia melalui penerapan model discovery learning dan media video dalam kondisi pandemi Covid-19 bagi siswa SMPN 2 Gangga. Jurnal Paedagogy: Jurnal Penelitian dan Pengembangan Pendidikan, 7(3), 210-215. doi: https://doi.org/https://doi.org/10.33394/jp.v7i3.2732

Tambunan, E., \& Bukit, N. (2015). Analisis pengaruh model pembelajaran kooperatif tipe group investigation dan pemahaman konsep awal terhadap hasil belajar siswa di SMA Negeri 1 Teluk Mengkudu. Jurnal Pendidikan Fisika, 4(1), 49. doi: https://doi.org/10.22611/jpf.v4i1.2568

Tarsono, T. (2018). Implikasi teori belajar sosial (social learning theory) dari albert bandura dalam bimbingan dan konseling. Psympathic: Jurnal Ilmiah Psikologi, 3(1), 29-36. doi: https://doi.org/10.15575/psy.v3i1.2174

Toyib, M. (2012). Penggunaan podcast dalam (STAD) untuk meningkatkan kemampuan menyimak pada mata kuliah listening prodi tadris inggris jurusan tarbiyah STAIN Ponorogo. Kodifikasia: Jurnal Penelitian Islam, 6(1), 1-21. doi: https://doi.org/10.21154/kodifikasia.v6i1.766

Yensy, N. A. (2020). Efektifitas pembelajaran statistika matematika melalui media whatsapp group ditinjau dari hasil belajar mahasiswa (masa pandemik Covid 19). Jurnal Pendidikan Matematika Raflesia, 5(2), 65-74. doi: https://doi.org/10.33449/jpmr.v5i2.11410 